\title{
REPRESENTAÇÕES DO ESPAÇO E FRANJAS PIONEIRAS PAULISTAS: UMA REFLEXÃO SOBRE O SILÊNCIO CARTOGRÁFICO
}

\author{
Representations of space and "Paulistas" Pioneer Fronts: a reflection on the cartographic \\ silence
}

\author{
Guilherme Caruso Rodrigues \\ Doutorando no IGCE/UNESP - Rio Claro/SP \\ gcarusorodrigues@yahoo.com.br
}

Artigo recebido em 16/09/2016 e aceito para publicação em 12/11/2016

DOI: 10.12957/tamoios.2016.23208

\begin{abstract}
Resumo
O presente trabalho aborda o mapeamento efetuado no período da expansão das Franjas Pioneiras no Estado de São Paulo. Partimos do pressuposto de Henri Lefebvre, que traz reflexões importantes do espaço, considerando-o como produto social, guardando inúmeras multiplicidades, portanto, resultado dum processo entrelaçado: de prática espacial, sendo a produção e a reprodução das relações sociais; de representações do espaço, atreladas ao modo de produção, que amarram as relações sociais, impondo uma ordem a estas e os espaços de representação, manifestados por meio dos símbolos das imagens e das significações próprias dadas ao contexto social. Assim, procuramos trazer para discussão a ocupação das Frentes Pioneiras concebendo-as como um conjunto de práticas espaciais, movidas pela internacionalização da economia capitalista, que almejava novos espaços para acumulação, dessa maneira, resultado de um movimento de objetivação prática sócio-espacial, caracterizadas pela derrubada de matas, implantações de ferrovias, espoliação exacerbada da renda da terra, transformando-se num espaço de representação conforme Léfèbvre, já que essas áreas se subordinavam ao grande capital internacional. Dentro desse contexto, propomos como discussão a relação dessas áreas consideradas pioneiras com seu processo de mapeamento. Adentrando no fato dos mapas como uma manifestação de poder, não só político como também econômico, gerando concepção espacial.
\end{abstract}

Palavras-chave: Franjas Pioneiras; Estado de São Paulo; Silêncio Cartográfico

\begin{abstract}
This work addresses the mapping that was done during the expansion of Pioneer Fronts in São Paulo State, between the decades of 30 and 40. We start from Henry Lefebvre's assumption that brings important reflections about space, considering it as a social product, and keeping its many multiplicities, therefore, the result of an interlaced process of: spatial practice, as the production and reproduction of social relations; representations of space, linked to production mode, which ties social relations by imposing them an order and the representation of space, manifested through symbols, images, and own meanings given to social context. Thus, we seek to bring into discussion the occupation of Pioneer Fronts, conceiving them as a set of spatial practices, driven by the internationalization of the capitalist economy, which aimed new spaces of accumulation, this way, the result of objectification movement of socio-spatial practice, featured by cutting down forests, railways implementation, exacerbated dispossession of land income, becoming a space of representation as LEFEBVRE, since these areas were subordinated to huge international capital. In this context, it is proposed to be discussed the relationship between these areas considered as pioneers with their mapping process. Talking about the fact of maps as a demonstration of power, not only political but also economic, it generates spatial concept.
\end{abstract}

Keywords: Pioneer Fronts; São Paulo State; Cartographic Silence 


\section{Introducão}

Durante a discussão acerca do processo de ocupação das frentes pioneiras, procuraremos entendê-las como mecanismo de representação do espaço. Trazendo à baila novas formas de apropriação, como já dissemos, calcaremos nossa análise, nas análises de Henri Léfèbvre para que haja esse entendimento. Faz-se necessário, uma vez que propomos, que haja nos mapas anteriores às Frentes Pioneiras toda uma intencionalidade, destacando a existência de áreas consideradas "vazias", ou seja que ainda não foram ocupadas.

Lefebvre nos aponta, baseado em Marx e Engels, que os homens como seres sociais produzem a vida, a história, a consciência, o mundo, abrangendo com isso multiplicidades diversas, isso como resultado do trabalho. $\mathrm{O}$ homem tem sua prática social, cria obras, modifica sua realidade e para isso é necessário trabalho. Nessa forma, há uma inseparabilidade de sua função, ou seja, numa constante dialética entre a forma e o conteúdo. Não sendo diferente para o espaço nas palavras do próprio autor:

Or, l'espace (social) n'est pas une chose parmi les choses, un produit quelconque parmi les produits; il enveloppe le choses produites, il comprend leurs relations dans leur coexistence et leur simultanéité : ordre (relatif) et/ou désordre (relatif). Il résulte d'une suite et d'un ensemble d'opérations, et ne peut se réduire à un simple objet. Pourtant, il n'a rien d'une fiction, d'une irréalité ou «idéalité» comparable à celle signe, d'une représentation, d'une idée, d'un rêve. LEFEBVRE (2000 p.89)

Defendemos a ideia de que as Franjas Pioneiras continham inúmeras relações que coexistiam num jogo de interesse marcado já a partir de seu processo de ocupação, embora devesse pensar que a ocupação era intencionada pelo movimento do modo de produção capitalistas. Havia na realidade um jogo de relações que permeavam essa ocupação, dentre essas, com a enorme possibilidade de ganhos financeiros a partir do cultivo de café para exportação, num jogo de interesse do capital, apoiado pela ação do Estado, visto que as exportações significariam também possibilidades de inserção cada vez maior do Brasil numa economia-mundo, bem como facilitações nos superávits das exportações. Não descontando com isso também, nesse jogo de relações a presença de povos nativos, caboclos que praticavam uma economia ainda de subsistência. Estava posta nessa complexidade o jogo marcado para dar significado à produção do espaço em questão e porque não uma territorialização. Nessa assertiva, concordamos com a visão dos geógrafos angloamericanos BRENNER; $\operatorname{ELDEN}(2009$, p.362) apontando que existe a produção do espaço pela sociedade dentro de um constante processo histórico. Dessa forma, se há uma produção do espaço, ele não é preexistente, mas sim coproduzido com o território dentro de uma totalidade dialética. Para esses autores, o território é a historicidade política do espaço, em que há a coexistência de táticas e de estratégias políticas associadas ao capitalismo moderno e ao Estado moderno, nesse campo de forças conduzindo a produção do "espaço-território". A produção e a reprodução do território se centram em ações do Estado, por meio de lutas políticas, seguindo a lógica do atual estágio do modo de produção capitalista. Por isso, a ocupação pioneira se pautava não só dentro de uma produção do espaço, mas também numa dialética de produção do território. Tratando-se de uma territorialização do capital, alavancada pelos pioneiros, encontramos aí mais um ponto de tal complexidade do processo de produção e de reprodução do espaço, com objetivos pré-definidos para que houvesse 
assim, uma relação de territorialização. Essa era a relação crucial para o pensamento da ocupação pioneira, os "espaços" ainda, supostamente, vazios abriam possibilidade para a ocorrência da territorialização do capital, com todo o seu aparato técnico, sobretudo a ferrovia, algo que daria uma ressignificância também na temporalidade, abrindo novas perspectivas para a relação espaço/tempo.

Outra discussão, que se faz necessária, advém novamente do pensamento de Lefebvre nas suas máximas espaço vivido, concebido e percebido. Segundo o autor, considerando que o espaço contém entrecruzamentos diversos, com uma enorme multiplicidade de situações, ele abarca uma triplicidade importante para se discutir.

Para Lefebvre( 2000, p. 42-43), o espaço se manifesta entre o percebido, em que se calca as práticas espaciais, atreladas aos momentos e aos valores da sociedade, que se produz e se reproduz conforme a sua singular formação social; as representações do espaço estão diretamente ligadas à ordem em que se dão a elas, sendo os espaços dos planejadores, que os concebem conforme seus signos e símbolos, mas que atendem às demandas socioeconômicas, que neste caso enfatizamos as ferrovias; já a terceira ideia perpassa acerca dos espaços de representação, em que estão presentes os simbolismos, ligados ao sutil da vida social.

Ainda dentro desta discussão, contrapomos estas premissas com as propostas de J.B. Harley, que nos traz uma ampla exposição de como os mapas e os contextos dos mapeamentos podem ser um mecanismo de poder. Carregando consigo, elementos de intencionalidade, muitas vezes visando a uma dominação. Algo que no nosso caso, abarca a necessidade de incorporação das Franjas Pioneiras Paulistas para a implementação do modo de produção capitalista nestas áreas. Os mapas coroaram isto, ao "silenciar" populações autóctones, e enfatizar esta região quase sempre como uma zona desocupada. Assim sendo, foi um meio de realizar a representação do espaço, conforme uma vontade vigente no contexto, a inserção da área na economiamundo.

\section{Elementos cartográficos do Estado de São Paulo, no fim do século XIX e início do XX}

A partir dos apontamentos acima é que pensamos nos mapas criados para demonstrar as Franjas Pioneiras que neles concentram diversas manifestações associadas à ideia de poder e de ocupação, estabelecidas na ideia de espaços vazios, conforme no mapa abaixo: 


\section{Figura 01}

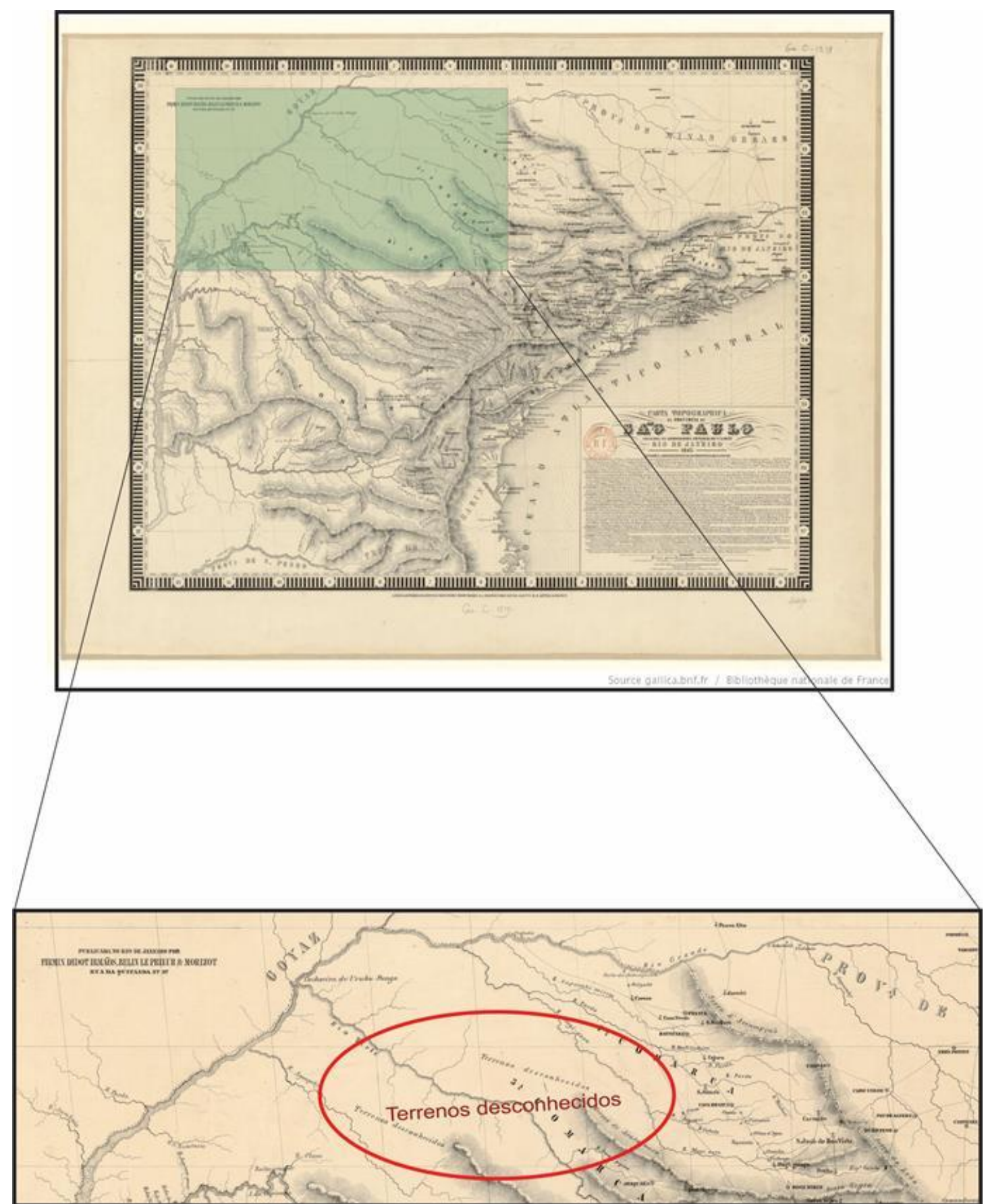

LOMBARD / J.H.. Carta topographica da Provincia de São Paulo. Petipé 20 legoas ao grao] / 1847.

Trata-se de uma carta topográfica da então província do estado de São Paulo, no ano de 1847, que apontava para o Oeste desse estado como zonas desconhecidas, embora já trouxesse até o final o deságue do rio Tietê, Paranapanema e Pardo, bem como seus respectivos divisores de água. Isso nos apresenta um elemento crucial para discussão que tão bem foi abordada por Harley (2005,p.67), segundo o autor, a ideia da topografia mostrada de forma "dura" sem considerar tanto o fato dos elementos que compõem o espaço, como comunidades tradicionais, grupos nativos no caso, brasileiro, ensejava uma relação de poder intencional do autor do mapa. Os elementos contidos no mapa de forma técnica apenas legitimam a ação de quem ainda vai ocupar 
o território, sustenta a ideia do "vazio", da área ainda a ser explorada. Conforme este mesmo autor, o mapa se faz como uma relação de poder, como um veículo na construção de certa subjetividade que alimenta meios de objetivação com o fim de produção e reprodução do espaço. Dessa maneira, o mapa pode apresentar certa dubiedade, com suas devidas intencionalidades, apontando ao mesmo tempo: o falso e o verdadeiro, a precisão e a imprecisão, objetivo e subjetivo, literal e simbólico. Mas que ao mesmo tempo se vê embebido de diversas relações sociais. (Harley, 2005,p.53). Ao depararmos com tal assertiva, podemos analisar que o mapa se insere dentro de um contexto histórico, mergulhado na cosmovisão social do momento de sua elaboração, a natureza social, política e econômica do momento. Ainda conforme Harley (2005,p.54), o mapa evidencia as forças políticas da sociedade. Tendo enorme influência em ações políticas e econômicas tornando-se uma ferramenta de coroação de ações futuras. Segundo o autor:

As much as guns and warships, maps have been the weapons of imperialism. Insolfar as maps were used in colonial promotion, and lands claimend on paper before they effectively occupied, maps anticipated empire. Surveyors marched alongside soldier, initially mapping for reconnaissance, them for general information, and eventually as a tool of pacification, civilization, and exploitation in the defined colonies. HARLEY (2005,p.57)

A citação acima corrobora a questão dos mapas serem confeccionados anteriormente à ocupação das áreas reivindicadas, servido eles com um vetor para futuras ocupações. Neste contexto, concordamos com o autor que os mapas e o processo de mapeamento não só eram um meio de reconhecimento de áreas, como também um mecanismo de impelir o processo de ocupação/colonização destas. $\mathrm{O}$ mapa dava legitimidade a estas ações.

Em vista disso, pautamos a hipótese que, na Figura 01, não se tratava de uma área desconhecida, uma vez que já se sabia os limites naturais dessas bacias hidrográficas e também havia uma ideia do limite político da então província com Goyaz. Algo que no submete a pensar numa intencionalidade para caracterizar a área com tal predicado. A conceituação da área como zona desconhecida, que se pode de certa forma utilizar como Frente Pioneira, já pressupõe, conforme o pensamento de Lefebvre, um espaço de representação, considerando que ali se abria precedente para que de fato houvesse a sua ocupação, baseada na produção do café, haja vista o período de elaboração dessa carta, ainda no século XIX, que subsidia o fato do café ainda se concentrar muito mais na porção leste da província. Outro fato é o que se passava no auge da comercialização dessa mercadoria, podendo significar ainda sua expansão no chamado Oeste Paulista. Assim, sendo desconhecido, e, precisando ser ocupado, cria-se outra representação: a de pioneiro. Caberia a estes a ocupação dessas áreas? A categoria pioneiro, de certa maneira legitima o processo de ocupação. Inclusive a demarcação de divisores de água, que posteriormente seriam utilizados com lócus para ocupação de ferrovias, segundo Monbeig (1998, p.40), eram construídas sobre os divisores de água, assim, justifica-se o fato de um mapeamento mais técnico, demonstrando, portanto, sua intencionalidade. No pensamento de Lefebvre isso se coloca como uma representação do espaço, ou seja, a concepção que de certa maneira, consolidaria o vivido, cuja intenção era mergulhar a área numa lógica do capital, que deveriam ser ocupadas pelas ferrovias. Embora, também já se contasse com a existência de comarcas nessas áreas, simbolizando a presença do Estado, que posteriormente entra como um agente no processo de ocupação. 


\section{FIGURA 2}

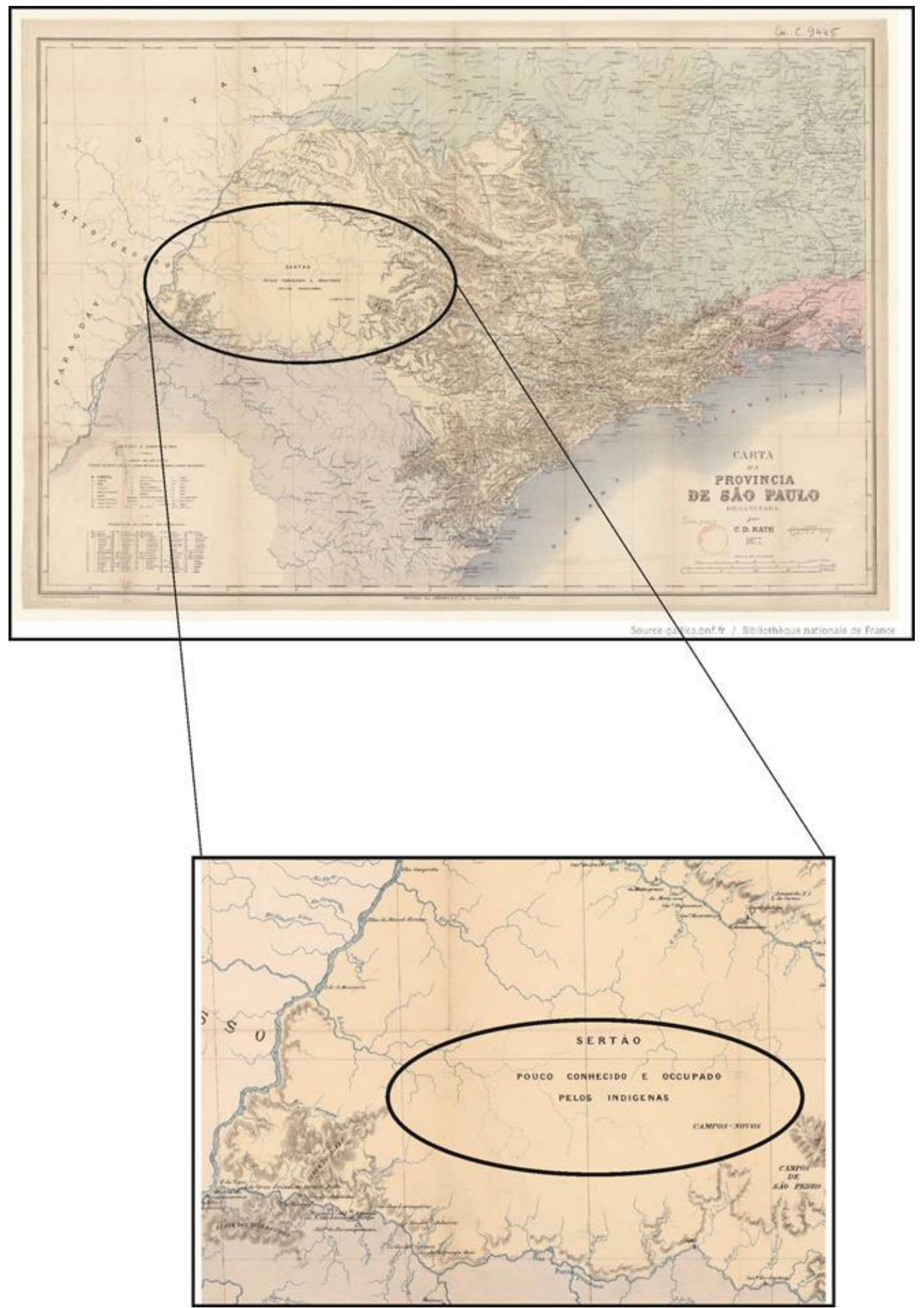

RATH, C.D. Carta da Provincia de São Paulo organisada por/1877

Em um grau de detalhamento maior, a Figura 02 expõe a província de São Paulo, no ano de 1877, indicando as principais aglomerações urbanas, que ainda se concentravam em sua maioria no Leste Paulista e novamente classificando o Sudoeste e região, hoje conhecido como Pontal do Paranapanema, como uma área, não mais desconhecida, mas sim ocupadas por populações indígenas, ou pouco ocupado. Nesse 
contexto, do subterrâneo, o espaço de representação, ao evidenciar o fato de ser pouco ocupado ou ainda ser tomado por populações autóctones, era uma área que deveria ter uma outra configuração. Assim, o questionamento que fazemos é: pouco ocupado por e para quem? E mais ainda, é descrito como área de campos novos. O que significa este novo? Abre-se então uma nova relação de poder e de formação de território a ser desbravada pelos chamados pioneiros, que necessariamente deveriam implementar uma lógica capitalista nessa área, tal qual já foi assumida pelo Leste Paulista. Neste mapa, já com as fronteiras bem definidas com a província do Paraná, anteriormente parte de São Paulo. Manifestando, desta forma, um meio de fragmentar as identidades de populações autóctones, apenas silenciando-as na sua representação, ainda que cartográfica.

A negligência da existência destas referenda a ocupação cuja finalidade era extração dos excedentes que a terra poderia vir a gerar. A priori, pela sua ocupação/colonização, e a posteriori pelo cultivo do café. A especulação da terra, através de seu parcelamento já se iniciava a partir deste silêncio cartográfico. Tais linhas silenciosas dão noção de certo vazio social. No contexto histórico da elaboração destes mapas, já o fizeram objetivando certo controle da área, dando um designo latente para a ordem social em questão. Ou seja, ocupar os vazios, para que a terra ganhasse um modo rentista de produção. Não deixa, assim, de gerar certa disciplina a estes, chamados fundos territoriais. Ainda conforme Harley (2005 p. 62) "They fixed territorial relativities, according to the lottery of birth, the accidents of discovery, or, increasingly, the mechanism of the word market".

Interessante pensar como no espaço geográfico, no seu processo histórico de produção e reprodução, anteriormente, criam-se noções de relatividades territoriais, denunciando assim, a real intenção advinda neste processo, que é a ocupação para a especulação rentista da terra, conforme, já mencionamos acima. Isso nos permite vislumbrar os reais elementos da formação sócio-espacial em questão. Através do simbólico consegue-se realizar o concreto. Uma ideia de ficção controlada, no âmbito da omissão das reais informações. Concordando com MOARES, A.C.R. (2011,p.59), "os discursos agem para a produção material do espaço, com o imaginário territorial abrem espaço para a apropriação dos lugares". Isso, nos permite também discutir, sobretudo a partir da Figura 02, que estes pontos considerados como sertão (algo que sugere estranheza na Geografia do Estado de São Paulo), porque conforme o mesmo autor se configura como um lócus para o diferente, para a ausência do outro, sendo o sertão uma condição que fora atribuída, um signo imposto ao chamado fundo territorial. É um tipo de discurso que o classifica dentro de uma mentalidade reinante para que houvesse sua ocupação efetiva, no entanto, com outro viés, o viés capitalista, ainda conforme o autor:

O sertão é comumente concebido como um espaço para a expansão, como o objeto de um movimento expansionista que busca incorporar aquele novo espaço, assim denominado, a fluxos econômicos ou a uma órbita de poder que lhe escapa naquele momento. Por isso, tal denominação geralmente é utilizada na caracterização de áreas de soberania incerta, imprecisa ou meramente formal. No geral, utiliza-se o termo sertão para qualificar porções que se quer apropriar dos fundos ainda existentes no território nacional em cada época considerada. Nesse sentido, trata-se de um qualificativo que induz um novo processo de domínio territorial sobre os espaços enfocados, isto é, que introduz um novo surto de dominação política no âmbito espacial delimitado pela qualificação proposta. $\operatorname{MORAES}(2003, \mathrm{p} .03)$ 
Com base nas palavras acima, o processo de mapeamento da área referida neste artigo, alcança meios para que haja tal dominação, legitima a tomada de poder do local, de modo a romper com a "soberania incerta". Tratar o Oeste Paulista como sertão dá subsídios para que se pavimentasse sua exploração, da mesma forma que negligencia o outro geográfico, e de certa maneira, aliena territórios. Configura uma relação conflituosa e assimétrica de poder entre a colonização e o sertão. Tanto que já há uma visão externa da região, apontada, nas entrelinhas como ponto estranho, embora já houvesse conhecimento de seus elementos físicos. É a ideia do imaginário que sustenta a sua ocupação concreta. No mapa acima, ainda fica bastante subentendido, diante disso, que o fato de ser pouco conhecido e ocupado por indígenas sugere a sua refuncionalização.

Algo bem nítido no recorte abaixo elaborado por R. Hausmman, 1918 (Figura 03), novamente todo o Oeste Paulista é mostrado como uma zona não explorada, confirmando o fato de estar aberto para uma nova funcionalidade econômica. Logo, sua lógica de ocupação por meio da exploração da terra, posto que uma vez que o contexto histórico ainda permeava a produção e a exploração do café, o grande produto que durante o período deu sustentáculo à economia brasileira.

\section{Figura 03}

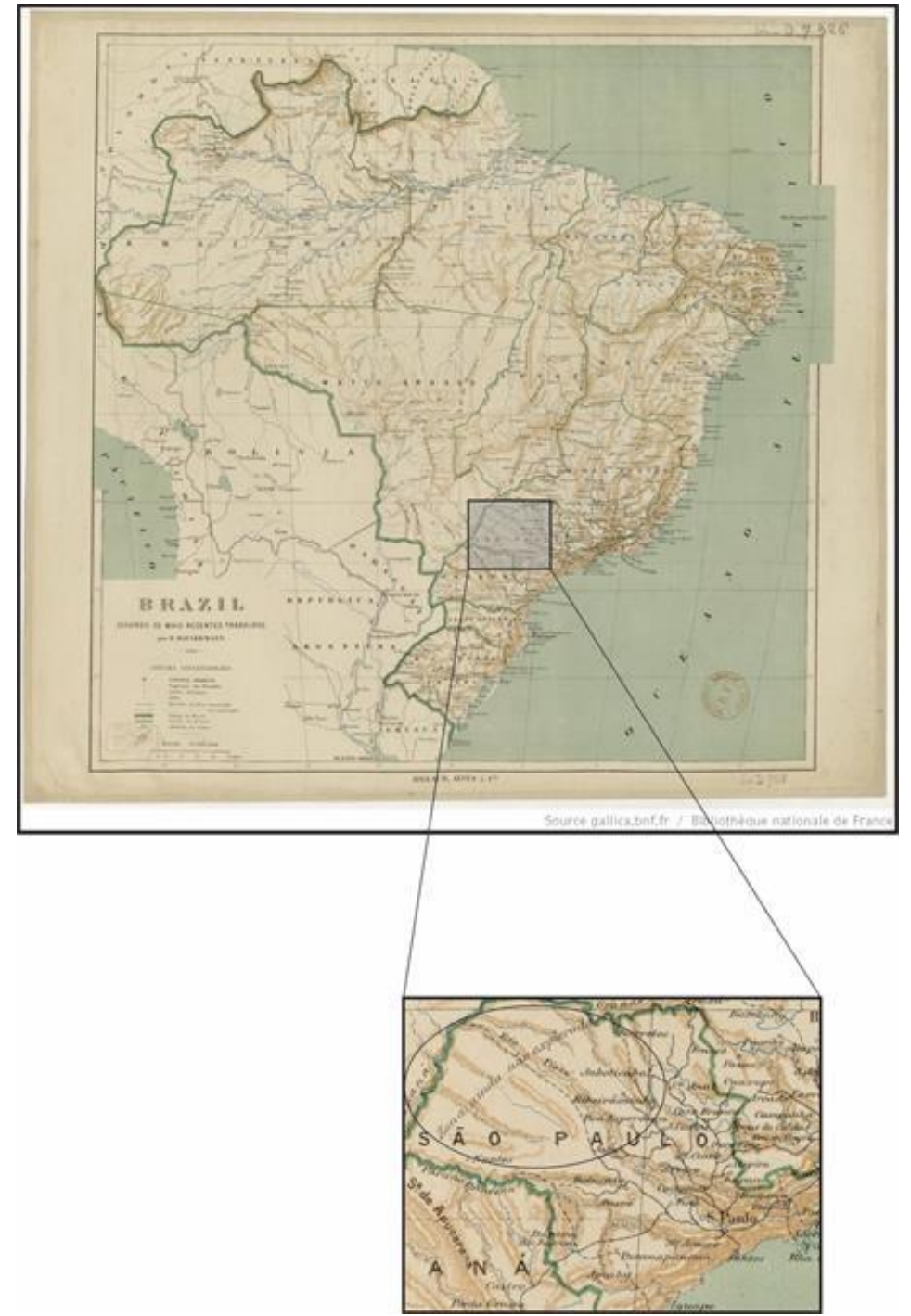

HAUSERMANN, R. Brasil segundo o mais recentes trabalhos / por R.Hausermann. 1918 (destaque nosso) 
Contrapondo com a carta de Enrico Croce, do ano de 1893 (Figura 04), as zonas pouco exploradas aparecem como áreas de florestas virgens, que na pesquisa de Pierre Monbeig, Pioneiros Fazendeiros do Estado de São Paulo, é descrita como áreas que foram derrubadas com o intuito de se produzir café, de se construir grandes fazendas, bem como a exploração da madeira, corrobora a função rentista que a terra necessitava possuir. Embutindo, portanto, o fato de que deve ser realizada a sua exploração, demarcando nesse espaço de representação a formação de uma prática sócio-espacial, seguindo a lógica do modo de produção capitalista, e a inserção, como um todo, de São Paulo ao novo modelo mais dinâmico a este novo modelo mais dinâmico. Por isso as Frentes Pioneiras, representadas cartograficamente dessa maneira, anuncia-se carregada de certa mundialidade. É de muita valia também que o mapa procura realçar a implementação de uma nova representação do espaço, ou seja, do espaço concebido para o melhoramento dessa nova ordem econômica, resinificando práticas espaciais.

\section{Figura 04}

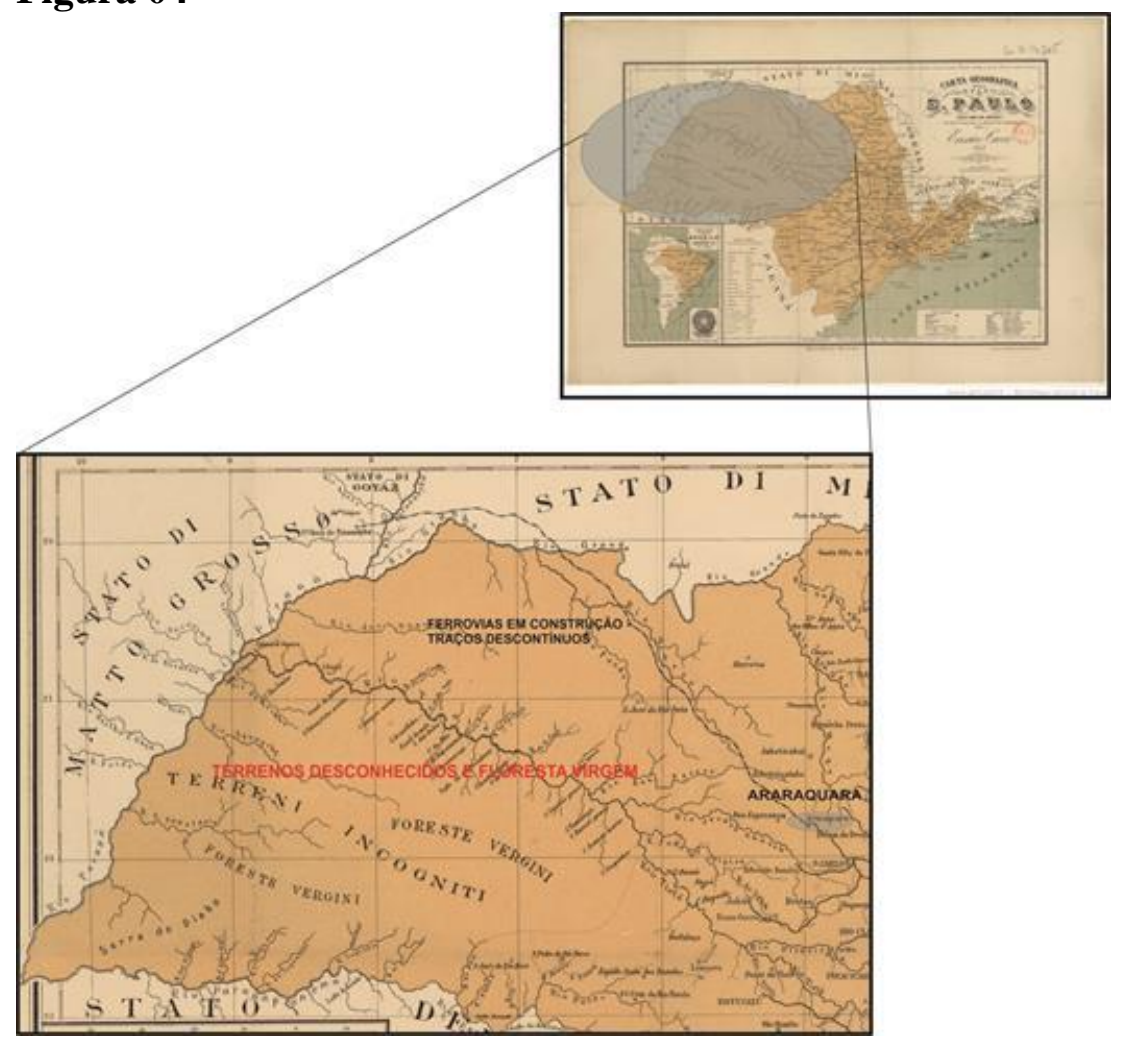

CROCE, E. Carta geografica dello Stato di S. Paulo (Stati Uniti del Brasile), Con tutto le Ferrovie in attivita ed in costruzione/1893. (Destque nosso)

Atentando para as ferrovias em construção a partir de Araraquara, num prolongamento de Ferrovia Paulistana (Paulista), como pode ser observado na legenda deste mesmo mapa em destaque (Figura 05). O que quer dizer que se tratava de novos lugares devendo ainda ser ocupados. A própria construção da ferrovia, já aponta para um meio de se eliminar capital excedente nos grandes centros, uma vez fora construída com capital inglês. Do mesmo jeito que chancelava o parcelamento futuro do solo. Ou seja, para que houvesse busca por novas áreas de expansão da cultura do café, considerando que é um mapa de 1893, algo justificado em inúmeros trabalhos, com o intuito de se ter uma boa produtividade na área em função do latossolo vermelho, que de fato garantiria uma excelente produtividade para a 
cafeicultura e exploração rentista da terra, consequentemente. A Cartografia, assim sendo, se coloca como um meio, uma representação de um discurso.

\section{Figura 05}

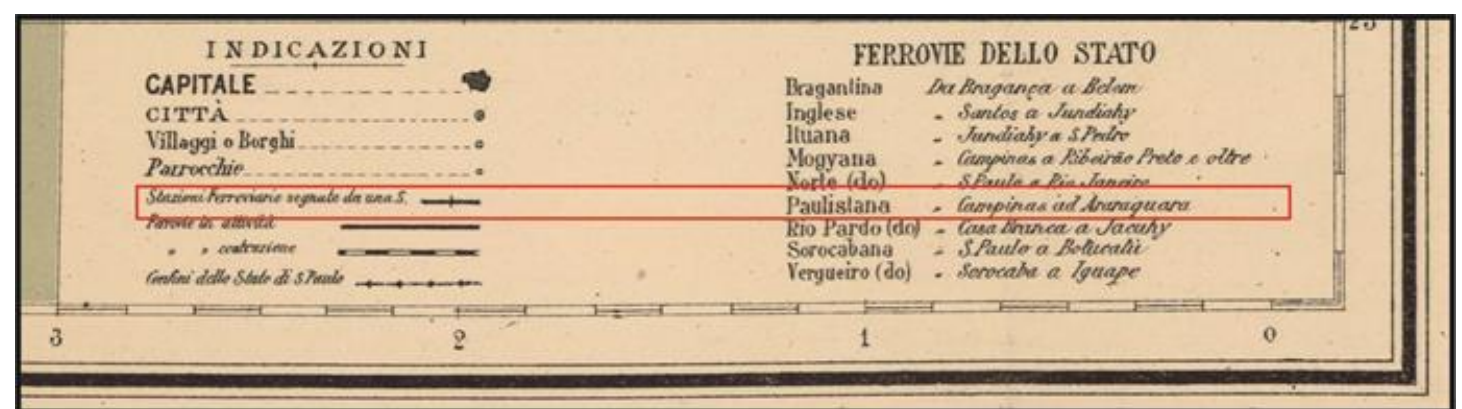

CROCE, E.Carta geografica dello Stato di S. Paulo (Stati Uniti del Brasile), Con tutto le Ferrovie in attivita ed in costruzione /1893.(Destaque nosso)

\section{Consideracões Finais}

Toda a significância do mapa deve partir para além da localização espacial dos lugares, o que se propôs, foi analisar o silêncio que pode estar contido neles. Isso não só ao omitir informações, como também trazer informações não correlatas ao real uso do espaço. Algo muito presente nos usos de termos como "desconhecidos", virgens, etc, no chamado Oeste Paulista, coincidindo com as chamadas Frentes Pioneiras, que no caso se propõe uma crítica ao termo. Ele por si só significa um espaço de representação, pois esconde o verdadeiro significado que foi o pioneirismo, ou seja, incorporar novas áreas para a implementação mais intensa do modo de produção capitalista. Por isso, pode-se afirmar que os mapas foram um meio de legitimação dessa incorporação, já que dava a ideia do vazio, de uma terra sem dono, pronta para ser explorada e espoliada. Não se entrará nesta discussão, mas bem se sabe que esse processo teve como um dos sustentáculos o Estado Brasileiro, que concebia nessas áreas, além dos superávits comerciais, um mecanismo de ocupação e de demarcação das fronteiras, ainda muito frágeis, embora se estivesse no limiar do século XX.

O mapa se coloca, dessa maneira como um construto social, veiculando uma visão de classe, procurando a incorporação do capital, os espaços de representação vazios se apresentavam no contexto de consolidar a lógica capitalista onde ainda não se via tal prática sócio-espacial, sendo assim, concebe-se um espaço emoldurando novas formações sociais, destruindo as anteriores. Consideramos que essas ferramentas cartográficas auxiliam a compreender melhor da chamada Geografia Histórica do período. O mapa é uma forma de discurso, portanto, com possibilidades de aderência ideológica ligada as formas, ações de exercício de poder. Sendo os mapas um veículo metafórico de contextos. 


\section{$\underline{\text { Referências Bibliográficas }}$}

BRENNER, N.; ELDEN, S. Henri Léfèbvre on State, Space, Territory. International Political Sociology, v.3, p. 353-377, 2009

CROCE, Enrico, Carta geografica dello Stato di S. Paulo (Stati Uniti del Brasile), Con tutto le Ferrovie in attivita ed in costruzione1893. 53x35 cm Escala 1:2.000.000, In.: Chemins de fer carta, Pisa: Stab. Lit. A. Bartolucci-Ghelli, 1893 , disponível em <http://gallica.bnf.fr/ark:/12148/btv1b8492426s/f1.item.r=croce\%20enrico $>$ Acessado em abril de 2016

ESCOLAR.M. Exploration, cartography and the modernization of state power. International Social Science Journal volume 49, issue 151 p. 55-75, March 1997

GOLDMANN, L. Ciências Humanas e Filosofia. O que é Sociologia? São Paulo/Rio de Janeiro: Difel, 1976. P.118

HAESBAERT,R. O mito da desterritorialização - Do "Fim dos Territórios" à Multiterritorialidade. Rio deJaneiro, Bertrand Brasil,2004 p. 395

HARLEY, J. B The new nature of Maps. Essays in the History of Cartography. Baltimore. JHU Press, 2002. P. 351

HAUSERMANN, R, Brasil segundo os mais recentes trabalhos de R. Hausermann, Paris, Aillaud, Alves et Cia, 1915, mapa, 465 x 475 cm., 1:10.000.000, disponível em:< Http://gallica.bnf.fr/ark:/12148/btv1b8446043s $>$ Acessado em abril de 2016

LEFÉBVRE,H. La production de l' espace. 4ªd.Paris : Anthropos, 2000, p. 485

LOMBARD, J.H. Carta topographica da Provincia de São Paulo. Petipé 20 legoas ao grão, Rio de Janeiro, F. Didot Irmaos, Belin Le Prieur et Morizot, 1847, mapa, 600 x 470 cm., 1:2.000.000. Disponível em:http://gallica.bnf.fr/ark:/2148/btv1b53024946z Acessado em abril de 2016

LÖWY,M.; NAÏR, S. Lucien Goldmann ou a dialética da totalidade. São Paulo: Boitempo, 2008, p. 190

MONBEIG, Pierre. As estruturas agrárias da faixa pioneira paulista. Boletim Geográfico, v. 11, n. 116, p. 455-465, 1953,

1940, p. 292

Ensaios da Geografia Humana Brasileira. São Paulo: Martins,

MONBEIG,P; LEVY-STRAUSS,C. Les indiens Nambikwara du Mato Grosso d'après Mr. Claude Levy-Stauss. Annales de Géographie, V. 60 n.322, p. 376-379. Armand Colin, 1951, Paris.

O Brasil. $4^{\text {a }}$.ed. São Paulo: Difusão Europeia do Livro, 1971, p.134 
1998, P. 392

Pioneiros Fazendeiros de São Paulo. $2^{\text {a }}$.ed. São Paulo:Hucitec/Polis,

MORAES, Antonio Carlos Robert. O Sertão. Um “outro" geográfico. P. 01 a 08, Terra Brasilis (Nova Série). Revista da Rede Brasileira de História da Geografia e Geografia Histórica, n. 4-5, 2003.

MORAES,A.C.R. Território, poder e justiça: comentários a partir da experiência brasileira. P. 130 a 141 In.:KRITSCH, R., RICUPERO, B.(org.) Força e legitimidade: novas perspectivas. São Paulo: Associação Editorial Humanitas, 2005, p.174

RATH, C.D. (org.) Carta da província de São Paulo, São Paulo, A.L.Garraux \& Cia., 1877, mapa, 825 x $555 \mathrm{~cm}, \quad 1:$ 1.500.000. Disponível em:http://gallica.bnf.fr/ark/12148/btvlb53098764p 